San Jose State University

SJSU ScholarWorks

Faculty Publications

Industrial and Systems Engineering

January 1994

\title{
Constraints on Initial AHS Deployment and the Concept Definition of a Shuttle Service for AHS Debut
}

Jacob Tsao

San Jose State University, jacob.tsao@sjsu.edu

Follow this and additional works at: https://scholarworks.sjsu.edu/indust_syst_eng_pub

Part of the Industrial Engineering Commons, and the Systems Engineering Commons

\section{Recommended Citation}

Jacob Tsao. "Constraints on Initial AHS Deployment and the Concept Definition of a Shuttle Service for AHS Debut" Intelligent Vehicle Highway Systems Journal (IVHS Journal) (1994): 159-173.

This Article is brought to you for free and open access by the Industrial and Systems Engineering at SJSU

ScholarWorks. It has been accepted for inclusion in Faculty Publications by an authorized administrator of SJSU

ScholarWorks. For more information, please contact scholarworks@sjsu.edu. 
This article was downloaded by: [T\&F Internal Users], [Lindsay Allen]

On: 17 September 2013, At: 06:36

Publisher: Taylor \& Francis

Informa Ltd Registered in England and Wales Registered Number: 1072954 Registered office: Mortimer House, 37-41 Mortimer Street, London W1T 3J H, UK

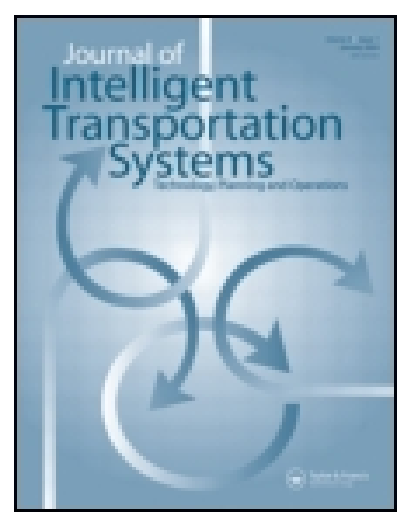

I V H S J ournal

Publication details, including instructions for authors and subscription information:

http:// www. tandfonline.com/loi/gits18

\title{
CONSTRAINTS ON INITIAL AHS DEPLOYMENT AND THE CONCEPT DEFINITION OF A SHUTTLE SERVICE FOR AHS DEBUT
}

\author{
H. -S. Jacob Tsao ${ }^{\text {a }}$ \\ ${ }^{a}$ PATH Program, Institute of Transportation Studies, University of California, Berkeley \\ Published online: 27 Feb 2007.
}

To cite this article: H. -S. J acob Tsao (1995) CONSTRAINTS ON INITIAL AHS DEPLOYMENT AND THE CONCEPT DEFINITION OF A SHUTTLE SERVICE FOR AHS DEBUT, I V H S J ournal, 2:2, 159-173, DOI: 10.1080/10248079508903822

To link to this article: http:// dx. doi.org/ 10.1080/10248079508903822

\section{PLEASE SCROLL DOWN FOR ARTICLE}

Taylor \& Francis makes every effort to ensure the accuracy of all the information (the "Content") contained in the publications on our platform. However, Taylor \& Francis, our agents, and our licensors make no representations or warranties whatsoever as to the accuracy, completeness, or suitability for any purpose of the Content. Any opinions and views expressed in this publication are the opinions and views of the authors, and are not the views of or endorsed by Taylor \& Francis. The accuracy of the Content should not be relied upon and should be independently verified with primary sources of information. Taylor and Francis shall not be liable for any losses, actions, claims, proceedings, demands, costs, expenses, damages, and other liabilities whatsoever or howsoever caused arising directly or indirectly in connection with, in relation to or arising out of the use of the Content.

This article may be used for research, teaching, and private study purposes. Any substantial or systematic reproduction, redistribution, reselling, loan, sub-licensing, systematic supply, or distribution in any form to anyone is expressly forbidden. Terms \& Conditions of access and use can be found at http:// www.tandfonline.com/page/terms-and-conditions 
IVHS Journal, 1995, Vol. 2(2), pp. 159-173 Reprints available directly from the publisher Photocopying permitted by license only (c) 1995 OPA (Overseas Publishers Association) Amsterdam BV. Published under license by Gordon and Breach Science Publishers S.A. Printed in Malaysia

\title{
CONSTRAINTS ON INITIAL AHS DEPLOYMENT AND THE CONCEPT DEFINITION OF A SHUTTLE SERVICE FOR AHS DEBUT
}

\author{
H.-S. Jacob Tsao \\ PATH Program, Institute of Transportation Studies, University of California, \\ Berkeley
}

Highway automation and its evolution involve a multitude of systems issues. Particularly important and difficult in defining a deployment sequence is the very first step, i.e. the first user service involving fully automated freeway driving. However, this importance and the difficulty imply that many factors may severely constrain the initial deployment.

After discussing the paramount importance of initial AHS deployment, this paper points out major high-level issues and constraints. Any realistic deployment strategy must take into consideration gradual technology maturation, introduction of new driver role and diminishing conventional driver role for automated driving, high cost of early-generation automationequipped vehicles, gradual infrastructure modification, gradual commitment of automakers to manufacture and service automation-equipped vehicles, gradual commitment of insurance industry to carry liability, and gradual acceptance by the interest groups and the general public. This paper then proposes a freeway shuttle van service for AHS debut. This user service could be a good candidate for the 1997 AHS demonstration required by ISTEA and has a good chance of leading to a successful long-term AHS deployment supported by the general public.

Key words: automated highway systems (AHS), evolutionary path, deployment issues, initial user service, shuttle van

$\mathrm{T}$ he concept of automated highway systems (AHS) was motivated primarily by its potential for large capacity and safety gains without requiring significant rightof-way acquisition. Operation in a freeway type of roadway has been assumed. It has been viewed by some as the ultimate solution to the worsening pervasive traffic congestion problem. The key areas for performance improvement, as stated in the Broad Agency Announcement (BAA) for the FHWA Precursor Systems Analyses of Automated Highway Systems [FHWA, 1992(b)], are: safety, throughput, user comfort and environmental impacts. Recently, Bishop et al. [Bishop et al., 1994] argued for the necessity to include moving people, as opposed to moving only vehicles (in terms of the number of passing vehicles per lane per hour), as an additional performance objective for AHS. He also emphasized that AHS is one of many tools for solving the problem of traffic congestion and should not be viewed as the ultimate 
solution. The service category of shuttle van to be proposed in this paper as the target for initial AHS deployment is consistent with this new objective and has the potential of being developed into various mature AHS, including a transitoriented AHS and an automobile-based AHS.

\section{AHS Design and Deployment Challenges}

The concept of highway automation began decades ago. (See, for example, [TRB, 1976; Elias et al., 1977; Shladover, 1979].) In a recent comprehensive treatment of conceptual AHS design, Stevens [Stevens, 1993] discussed AHS deployment and operations goals, analyzed AHS characteristics and identified 37 alternative AHS concepts. With a narrower scope, Tsao et al. [Tsao et al., 1993(a)] recently identified many major design options and issues for operating fully automated AHS. They also addressed the impacts of the options on major AHS performance criteria including safety, capacity, human factors, infrastructure, cost, etc. Mostly due to the AHS Precursor Systems Analyses [FHWA, 1992(b)], systems research for AHS has enjoyed a recent surge of attention. A large number of AHS operating scenarios have been developed and many important issues have been identified and studied. However, the vast majority of the scenarios did not address how to evolve the current highway systems toward mature AHS.

\section{The Great Need for Research on Evolutionary Paths to Mature AHS}

For an AHS human factors project funded by the FHWA [FHWA, 1992(a)] and based on [Tsao et al., 1993(a)], Tsao et al. [Tsao et al., 1993(b)] developed seven AHS operating scenarios and presented them at a workshop on AHS human factors [FHWA, 1993]. A consensus reached at the workshop was that more research was needed on the design of evolutionary paths to AHS. Because of the many AHS design options, there exist a large number of different mature operating scenarios. The dimension of evolution leads to an even larger number of possible evolutionary scenarios.

Al-Ayat and Hall [Al-Ayat and Hall, 1994] developed a framework for planning the evolutionary deployment of all IVHS technologies and provided examples of evolutionary deployment sequences. Design of such sequences at this stage is a difficult task because of (a) the sheer large number of possible evolutionary AHS operating scenarios, (b) the existence of many technical and non-technical issues and uncertainties and (c) the difficulty in predicting scenario performance under these uncertainties. Recently, Hall and Tsao [Hall and Tsao, 1994] identified many factors that may dictate the feasibility of a given AHS system and organized them in a simple influence diagram. They also identified many specific AHS feasibility issues and uncertainties. 


\section{Focus on Initial Deployment and Motivation}

Particularly important and difficult in defining a deployment sequence is the very first step, where the first step is defined as the first user service that involves fully automated freeway driving (i.e. hands-off and feet-off). The importance of the first step and the difficulty in its determination imply that many factors may severely constrain the initial deployment target and there may not be many choices. It is this observation and the approaching congressional mandate (Intermodal Surface Transportation Efficiency Act of 1991 or ISTEA for short) to demonstrate the viability of AHS through a prototype in 1997 that motivated our focus on initial AHS deployment.

Since AHS is motivated by the great need to relieve highway traffic congestion and traffic congestion (given the current land-use pattern and life-style in the U.S.) seems relievable only by providing more highway capacity for automobiles (or, more precisely, single-occupancy vehicles), automobile-based AHS could be the only viable option, compared to other types of AHS, e.g. transit-based AHS. However, it is not necessary that automobiles should be the very initial automation target.

FHWA Administrator Slater [Slater, 1994] called on the IVHS research and development community to "put the taste of IVHS in people's mouth". Since AHS is the most technology-intensive and perhaps the most costly component of IVHS, his call is particularly important for a sustained public interest and support of AHS research and development. The proposed initial deployment target can be used to entice the general public.

\section{Purpose and Organization of the Paper}

This paper first discusses the great importance of selecting a proper initial deployment target and then identifies major issues and constraints for initial deployment. It then proposes the service category of shuttle van as the initial target. After describing an automated freeway shuttle van service, this paper discusses the many advantages and some possible issues. This paper focuses on the concept definition. Feasibility issues and cost-benefit require further study. It turns out that this particular selection does not constrain the direction of future AHS development. In other words, the proposed selection can be developed into many different mature AHS systems.

\section{IMPORTANCE OF INITIAL AHS DEPLOYMENT}

The strategy for initial AHS deployment is crucial because it must be able to not only set the stage for further technological development but also ensure continued public interest and support for AHS. Due to the existence of many possible AHS design options [ Tsao, et al., 1993a; Stevens, 1993; Stevens, 1994], there exist many different possible mature AHS. Given these multiple possible "end states" as well as the multiple severe initial deployment difficulties, an ideal initial deployment strategy 
is one that not only helps the AHS technologies break into the conventional transportation market but also imposes no constraints on the reachability of the multiple possible end states.

Due to the many possible AHS design options, it is easy to lock one's mind to some particular options, argue against their feasibility or acceptability and then declare the infeasibility or undesirability of AHS as a whole, as if those particular options are absolutely necessary for any AHS. In fact, AHS should be viewed simply as any highway system that can benefit from automated driving enabled by integrating sensor, communication, computer, and control technologies. Such automation technologies can be applied in many ways, not just those ways that would encourage only solo-driving. For example, given the sprawling suburbs designed for solo-driving, conventional mass-transit based on full-size buses may not be convenient and economically attractive enough to lure sufficient ridership for its survival. The highway automation technologies may be tailored to automate the highway driving of a van/ mini-bus shuttle system and, together with other transit technologies, may eventually lead to an automated transit system.

Some AHS design options could inadvertently lead to public misconception about AHS. The concept of close-spaced platooning (for capacity gain) is now used to bring out several possible misconceptions of AHS. Platooning could very well be technologically feasible, safe and acceptable by the people, after a successful demonstration of the viability of the technologies. However, we should endeavor not to let people be misled into equating platooning with AHS before the required technologies have been proven and human factors issues have been resolved. A perhaps more serious issue is that platooning may conjure up the image of highways packed with automobiles. This may lead to the misconception that the only goal of AHS is to accommodate as much driving as possible and AHS could contribute nothing to encouraging ride-sharing and public transit. (Recall the objective of people moving argued for by Bishop et al. [Bishop et al., 1994].) Some people may believe that only "rich people" could benefit from AHS and even that public agencies would use public money to subsidize the deployment of AHS only to benefit rich people. Some example typical arguments against AHS can be found in [Lowe, 1993].

AHS researchers should be careful about presenting ideas to the general public; otherwise, we may inadvertently invite unnecessary hostility. Particularly important is the 1997 AHS demonstration required by ISTEA. That occasion could be the very first introduction of the concept of AHS to the general public.

\section{MAJOR ISSUES AND CONSTRAINTS FOR INITIAL AHS DEPLOYMENT}

Any realistic deployment strategy must take into consideration the following seven categories of issues: gradual technological maturation, introduction of new driver role and diminishing conventional driver role during automated driving, high cost of early-generation automation-equipped vehicles, gradual infrastructure modification, gradual commitment of automakers to manufacture and service automation-equipped vehicles, gradual commitment of insurance industry to carry liability, and gradual 
acceptance by the interest groups and the general public, particularly in terms of user service, safety, perceived safety, cost and environment impact. The impact of these issues is particularly acute during initial deployment and could be viewed as constraints. These issues are discussed in the following seven subsections.

\section{Gradual Technological Maturation}

Like many other technologies, automation technologies as well as the associated manufacturing and maintenance technologies will mature gradually. Faced with the uncertainty of market penetration, initial industrial investment in research, development, marketing and manufacturing may be small and gradual. Therefore, initial deployment is likely to consist of simple and proven technologies and yet useful user services. Based on earlier successes as well as public acceptance, technologies will then be further developed, refined and proven. This characteristic could impact the whole AHS evolution process. More explicitly, initial AHS deployment should enable continuous fully-automated and safe lane-travel (traveling along a lane without lane changing). It may also include automated lane changing and automated merging (i.e. merging of an automated vehicle into the existing traffic on a neighboring continuing lane at the location of lane drop).

To ensure safe automated driving, automation-equipped vehicles may need to be inspected and maintained frequently and rigorously. This could be a disincentive for car buyers to purchase an automation option. However, it could be more easily accommodated by a fleet operator.

\section{Introduction of New Driver Role and Diminishing Conventional Driver Role for Automated Driving}

Tsao et al. [Tsao et al., 1993(b)] identified many possible human factors issues for normal AHS driving. Resuming manual control of the vehicle after a period of fully automated driving is a new task for drivers. Tsao et al. [Tsao et al., 1994] identified many possible AHS failure events that might require human intervention in vehicle/ system operation for safety, especially in the early stages of deployment when the automation technologies have not been perfected yet. Emergency handling could also be part of the new driver role.

Human errors account for about $90 \%$ of the current highway traffic accidents and vehicle/highway automation has the potential of eliminating all accidents caused by driver errors. However, such automation requires additional equipment on the vehicle as well as on the roadside and could introduce new kinds of safety hazards. Before the maturation of these automation technologies, the driver may be required to play an active supervisory role monitoring the operation of the automated vehicle. On the issue of transition into and back from the automated driving mode, it is possible that initial automation technologies, due to cost and other constraints, cannot offer user-friendly transitions. Consequently, additional driver skills may be required. 
The requirement for transitional skills, the monitoring role and the emergencyhandling responsibility may necessitate driver training, which is not likely to entice car owners to purchase automation options. In fact, it is possible that, during initial deployment, only trained professionals, e.g. professional drivers with additional AHS training and credential, would be qualified to invoke automated driving.

\section{High Cost of Early-Generation Automation-Equipped Vehicles}

Like most other products employing new and sophisticated technologies, e.g. computers, the cost of the early-generation automation-equipped vehicles will likely be expensive to purchase and to maintain. Therefore, the high cost of such vehicles may hinder market penetration if individual car owners are the targeted purchasers. However, such a cost can more easily be absorbed by fleet operators, public or private, and only a small fraction of it will be passed onto each of its users. This parallels the initial introduction of computers into the market where sales of high-cost earlygeneration computers were targeted at large businesses and public agencies. This also parallels the installation of a collision warning device on Greyhound buses.

\section{Gradual Infrastructure Modification}

To accommodate automated driving, some infrastructure modifications are likely to be required. Possible infrastructure modifications include check-in (inspection) facilities at entry points, installation of lane markers, traffic monitoring devices, roadside controllers, and roadside-vehicle communication devices. Note that checkin facilities may require real estate at the highway-to-street intersections. If a buffer is needed to accommodate queueing, more real estate may be needed. To provide continuous automated driving from one freeway to another, additional automated connector ramps are needed. Special on-ramps and off-ramps may also be required at highway-to-street interchanges.

Some operating scenarios require more such modifications than others. Car buyers are not likely to purchase an automation option if not much of their driving can be automated because of lack of supporting infrastructure. On the other hand, demand shortage does not justify speedy infrastructure modification. (A chicken-and-egg phenomenon.) A better coupling of demand and infrastructure modification is to provide such modifications only where there is demand for it (i.e. where automated driving is wanted). In particular, modifications can be made to enable automated driving from one point on the freeway to another. In this way, if there is a need for an inspection facility at the on-ramp, which could be costly, such facilities can be added gradually. Note that a modified point-to-point segment can be the freeway portion of a fixed popular route. Through time, infrastructure modification can be completed for automated driving from any entry point on an urban freeway network to another. Individual car purchasers may then be enticed to select an automation option. 
For developing alternate IVHS deployment strategies, Al-Ayat and Hall [Al-Ayat and Hall, 1994] adopted six guidelines, including (i) functionality provided at each step is useful by itself and does not require full deployment of subsequent steps and (ii) each deployment step has a high likelihood of acceptance by the user. Item (i) implies that even if deployment is halted, the deployed functionality should continue to provide useful service. These two guidelines are particularly important for infrastructure modification.

\section{Gradual Commitment of Automakers to Manufacture and Service Automation- Equipped Vehicles}

The automakers will not commit their resources to making and servicing automation-equipped vehicles unless there is a profit to be made. It is well-known that, at the present time, a full-scale deployment of AHS technologies is full of uncertainties. To enter the business of making automation-equipped vehicles, they may prefer to start with a smaller but less uncertain niche than a much bigger but very uncertain market. Therefore, identification of an initial niche vehicle market for the automakers could be crucial.

\section{Gradual Commitment of Insurance Industry to Carry Liability}

Even today in many States, it is a legal requirement that each vehicle be insured for liability. This requirement will most likely remain after AHS deployment, if not made more stringent. Therefore, the interest and the attitude of the insurance industry must be taken into consideration. Incremental introduction of automation features that have proven safe may be required. Frequent and rigorous vehicle inspection and maintenance may also be required. Suppose that liability insurance will become available initially. Upon introduction of automated driving on highways, premium and/or deductible may be high for individual owners of automation-equipped vehicles. However, fleet operators could afford it more easily and distribute the additional cost to the individual service users. Without liability insurance, owners of automationequipped vehicles have to be self-insured. But, it is likely that such self-insurance is allowed only for large businesses or government agencies.

\section{Gradual and Incremental Acceptance by Interest Groups and General Public}

AHS research and development community must strive to win the acceptance by various interest groups and eventually the general public. It could win their support by offering products that appeal to them, particularly in terms of user service [Bishop et al., 1994], safety, perceived safety, comfort, convenience, reduced travel delays, cost and environment impact. However, that may not be sufficient; we need to learn from the failures and successes experienced by other industries in introducing new products. Tsals et al. [Tsals et al., 1993] studied four examples (Global Positioning Sys- 
tem, Bar Coding, Nuclear Power and Magnetic Resonance Imaging) and argued for the necessity to be (a) forthright with eventual customers about benefits and drawbacks of new technologies and (b) sensitive to public perception of new technologies (which may be different from reality).

To ensure achieving the full potential of automation, we should assume that interest groups and general public may reject AHS quickly but would accept it only gradually and incrementally. Phases of deployment must be carefully determined and implemented so that interest, trust and continued support by the general public can be cultivated.

\section{AHS DEBUT: A SHUTTLE VAN SERVICE WITH AUTOMATED FREEWAY DRIVING}

This paper proposes the service category of freeway shuttle for initial AHS deployment. This service is defined as one that (i) provides non-stop passenger transportation from one activity center to another, (ii) makes a small number of stops at each activity center to pick up and drop off passengers and (iii) uses mainly freeways for the entire trip. The familiar airport-to-downtown shuttle services currently available at most metropolitan airports are good examples for this service category. Note that the size of the shuttle vehicle can vary from full-size buses to mini-bus to van. However, small bus or large van could be preferred because (i) the resulting automation technologies may be applicable, with some modification, to both full-size bus and automobile, (ii) emergency control of vehicle may be easier or collision impact may be minimized during emergency maneuvers after vehicle/system failures and (iii) the demand for such a shuttle service may grow only gradually. Also note that such a freeway shuttle service could also link one suburb to another if demand is sufficient and local pick-up and drop-off are made convenient enough for riders.

Two possible operating scenarios for the shuttle van service, one for the early phase within the initial deployment and the other for the advanced phase, are defined as follows. These concept definitions are given at the functional level. Some details are omitted and there exist many variations to these scenarios.

\section{Initial Operation}

For discussion simplicity, let us focus on a particular shuttle van service between two activity centers and make the following assumptions:

(IOA1) There are no automated on-ramps or off-ramps at the two activity centers. But, there is one continuous HOV lane (leftmost lane) in each direction connecting the two centers.

(IOA2) Markers - paint markings, magnetic markers or other devices-are installed for vehicle lane-keeping. There is no other infrastructure support and roadside intelligence.

(IOA3) Shuttle vehicles are autonomous and sufficiently equipped for safe automated lane travel, i.e. cruising along a lane without lane changes, including both Adaptive Cruise Control (ACC) and automatic lateral control for lane- 
keeping. No vehicle-to-vehicle or vehicle-to-roadside communication capability is present.

At the very beginning phase during the initial deployment, shuttle van operation is very simple. It is summarized as follows:

(IO1) A driver is at the driver seat throughout the trip. Driving is manual while the vehicle is off the HOV lane.

(IO2) Upon entering the HOV lane and at a safe distance behind the vehicle (possible manually driven HOV) ahead, the driver invokes the automated driving mode and relinquishes manual control.

(IO3) During automated driving, the driver supervises the automated driving, reacts to possible vehicle/system failures, watches for possible debris ahead, reacts to possible dangers caused by the manual traffic in the HOV lane or its neighboring lanes. (A typical reaction to the failures or the abnormal driving conditions is driver's taking over vehicle control.)

(IO4) When judged appropriate by the driver, the driver takes over manual control to avoid potential dangers. If the HOV lane is blocked, the driver takes over control and changes lanes to bypass the blockage.

(IO5) When approaching the destination, the vehicle requests resumption of manual control. The driver then takes over manual control and drives the vehicle off the freeway to complete the journey.

(IO6) Shuttle vehicles are maintained and certified periodically and checked for fitness for automated driving frequently. Fitness checking is performed away from the freeway on-ramps, perhaps at the fleet operator's maintenance facilities.

\section{Advanced Operation within Initial Deployment}

With more assumptions as follows, advanced features could be accommodated.

(AOA 1) On-ramps and off-ramps dedicated to the direct entry of HOV traffic onto the HOV lane are available at both ends. (If all interchanges along the route are equipped with dedicated HOV on-ramps and off-ramps, the HOV lane can be isolated with barriers from the rest of the traffic for entry control and safety.)

(AOA2) Automation-equipped vehicles entering from these HOV on-ramps switch into automated driving mode on the on-ramps and merge, automatically and safely, with the existing traffic on the HOV lane. After leaving the HOV traffic and entering the off-ramp, automatically and safely, automated vehicles switch back to manual control on the off-ramp.

(AOA3) Roadside control system monitors the traffic on the HOV lane and warns the shuttle of any safety hazard ahead.

(AOA4) During automated driving, if and when the lateral control malfunctions, i.e. invading into a neighboring lane, it can detect the lane departure by an onboard warning system that is independent of the lateral control system (which had just failed). Upon detection, it decelerates rapidly and, in the mean time, gives both audio and visual warnings to its driver as well as the surrounding vehicles. (Independent emergency steering system or steering 
system redundancy ensuring safe return to lane, while decelerating, can also be explored.)

(AOA5) During automated driving, if and when the longitudinal control malfunctions, e.g. invading into the safety spacing between itself and the vehicle in front, the vehicle can detect the malfunction by itself and automatically engage the emergency brake. In the mean time, it gives both audio and visual warnings to its driver and the neighboring vehicles.

Possible more advanced operational features of this initial deployment include:

(AO1) The entire freeway portion of the trip starting at the on-ramp and ending at the off-ramp is fully automated, as long as a continuous HOV lane is available in between.

\section{Beyond the Initial Deployment}

At advanced deployment stages beyond this initial deployment, more advanced features can be added to the freeway shuttle service. In particular, under the following two assumptions, "unmanned" freeway driving could be safely implemented.

(AOA6) Dedicated on-ramps and off-ramps as defined in (AOA1) have become widely available and the HOV lane is completely or virtually completely separated from its neighboring lane by physical barriers.

(AOA7) During the rare event of vehicle/system failure, any passenger can pull an "emergency cord" to stop the vehicle. (Such devices are equipped on trains.) The new feature can be summarized as follows:

(AO2) Driver gets off the automation-equipped vehicle at the on-ramp and freeway driving is entirely automated without driver's supervision. Another driver gets on the automation-equipped vehicle at the off-ramp and completes the rest of the trip.

Without requiring a driver on-board, highway automation can realize another major benefit-saving of labor cost-as many other automation technologies often do. Note that such unmanned freeway shuttle service is not intended for initial AHS deployment due to safety considerations.

In this advanced deployment stage, absence of a driver during automated freeway driving will be an issue. Further study is required. If this is not acceptable, then a driver should be present throughout the trip. This way, operating cost would be higher than otherwise. But, the supervising-only role of the driver could reduce driver fatigue, which could in turn also increase safety off the freeway as well as improve driver's "quality of work life".

\section{ADVANTAGES AND POTENTIAL ISSUES OF AUTOMATED SHUTTLE VAN SERVICE}

The advantages and potential issues are grouped according to the seven issue categories. 


\section{Simple Technology and Operation for Nurturing AHS R\&D}

The initial operation of this automated freeway shuttle van service uses simple technologies, with respect to the sophisticated technologies required for a safe operation of various mature AHS systems. The operation is simple too. Winning public trust of the automation technologies is easier this way. Based on the likely success as well as public acceptance, technologies will then be further developed and proven. Inspection and maintenance can be accommodated by the fleet operator without much difficulty. The safety of such a service and the safety requirements should be rigorously studied. Other feasibility issues and cost-benefit require further study.

From the view point of technology, this initial service can be evolved into many possible mature automated highway systems, including an automobile-based fully automated AHS and a transit-oriented automated freeway shuttle system. A van/ mini-bus urban/suburban automated freeway shuttle system could be made convenient and economical enough to attract a sufficient amount of ridership for its operation because of (a) minimization of freeway travel delay/travel time, (b) possible cost reduction due to unmanned freeway driving (at an advanced deployment stage), (c) possible safety improvement due to elimination of driver error, (d) the demandresponsive transit technology [Teal, 1994] and other technologies that make access to the shuttle more convenient, (e) lower cost of operating vans and mini-bus (compared to full-size buses), (f) other transit technologies [Fisher, 1993]. Borrowing from a wealth of previous studies on the concept of "hubbing" by the airline and telecommunications industries, a region-wide freeway shuttle transit system which enables connection of any two major activity centers through at most one transfer could be possible. The cost-benefit and market potential of such an automated freeway shuttle system need to be thoroughly studied. Note that this system, if deployed alone, may not be viable; other technologies, particularly transit technologies, must be exploited to make it work. Also note that initial subsidy to the fleet operator may be needed.

Koppelman et al. [Koppelman et al., 1993] pointed out that incentives to rideshare, in the form of service improvements and price reductions, increase the propensity to use the mode of rideshare. Important service attributes of ridesharing include convenience and independence, timely service and price. The freeway shuttle transit system could improve all these three attributes.

\section{Safe Introduction of New Driver Role and Reduction of Conventional Driver Role For Automated Driving}

During initial operation of the shuttle service, the shuttle driver can be trained to perform the transitional tasks, monitoring role and emergency-handling. The roles of monitoring and emergency-handling are particularly important at the initial deployment stage while the technologies have not been perfected yet. After the initial stage, these roles may no longer be needed and the general driving public would have to learn about only the transitional tasks.

The professional drivers' input regarding (a) the degree of difficulty associated with the transitional tasks, (b) different design options for the transitional procedure 
and (c) user interface can be used for technology improvement. If the initial automation technologies, due to cost and/or other constraints, cannot offer user-friendly transitions, then the trained professionals can operate the automated vehicles while the automation technologies are being refined. The general public has to learn to use (and can certainly benefit from) the proven user-friendly design and user interface when they become available.

From the overall human factors perspective, the goal should be that the car owners do not have to endure the "growing pains" of the automation technologies but would only have to use the safe and user-friendly technologies that have been tested, improved and proven based on the experience gained during initial deployment.

\section{Sharing of High Cost of Early-Generation Automation-Equipped Vehicles}

Through sharing of costs (including those of purchase, maintenance, insurance etc.) by the individual service users, AHS technologies could become economically viable. Also because of the cost sharing, more sophisticated technologies, in terms of safety, can be explored, developed and implemented. This would lead to a safer initial deployment, whose importance simply cannot be over-emphasized. (The cost of such technologies will come down after mass-production and the mass-production prices may be eventually comparable to those of possible inferior technologies with lower initial prices.)

\section{Gradual Service Expansion Synchronized with Infrastructure Modification}

Dedication of HOV lane has become very popular and its presence will likely become a norm rather an exception. The technical difficulty and cost of infrastructure modification on the HOV lane depend on the actual automation technologies adopted for supporting the shuttle service. For vision-based systems, painted markings may suffice. For systems based on magnetic markers, although the magnets are inexpensive, their installation may not be trivial. Prioritization of modification projects can be synchronized with the transportation needs.

In the proposed initial operation, there is no need for new highway-to-highway connector ramps dedicated to HOV. The driver can manually change highways. For the advanced phase of initial deployment, the required infrastructure support includes a continuous HOV lane from one activity center to another as well as the dedicated HOV on and off ramps. Without the availability of a dedicated HOV connector ramp to another highway, continuous automated driving on to that highway is impossible. (Therefore, such connector ramps are required for the unmanned driving at the advanced deployment stage.) Note, however, that dedicated highwayto-highway connector ramps are needed even more for an automobile-based AHS. Without them, not only automated driving would be disrupted, the increased number of lane-changing vehicles (for changing highway through the conventional connector ramps) could create additional congestion. 
Since fitness checking (check-in) can be done off the freeway, there is no need to add check-in facilities at the on-ramps. Note that available real estate for the check-in facilities at highway-to-street interchanges may be quite limited. Since the objective during the proposed initial deployment is not to increase the freeway capacity in terms of vehicle throughput (i.e. number of vehicles per lane per hour), the deployed shuttle vans would not increase the number of vehicles using the freeway system. In fact, they have the potential of decreasing the number. This contrasts with the potential interface problem between the freeway and the city streets associated with an automobile-oriented deployment target, due to a potential significant increase of. automobiles. This interface problem will be more severe at highway-to-highway interchanges if no direct highway-to-highway connection enabling continuous automated driving is available. A related advantage, as compared to an automobile-oriented initial deployment, is that there is no need to augment the parking facilities near the work centers during the initial deployment.

If AHS development is stopped for some reason, the dedicated HOV access to the freeway system remains useful. Otherwise, individual owners would be more willing to purchase automation-equipped vehicles when infrastructure modification is sufficiently extensive.

\section{Initial Niche Market for Automakers and Leverage}

The demand for this category of services needs to be carefully estimated. Several factors point to its potential. In its initial operation, although the cost of this type of services cannot be lower than its manual counterpart, it could be safer. In the more advanced deployment stages where no driver is needed on freeway, the cost saving could be substantial and the demand for the shuttle service may be significant. With the niche market, automakers can reinvest the profit for further technology development.

\section{Reduced Risk for Insurance Carriers}

In the initial operation, only simple automation technologies are used and they are also backed up by professional drivers in the event of vehicle malfunction. The fleet operators are required and are able to maintain and inspect the vehicles frequently and rigorously. These could greatly reduce the accident rate and lead to vehicle insurability at an affordable premium. The database of accident data establishable during the proposed initial deployment can be used to argue for low rates. Even if a high rate of insurance premium is inevitable, a fleet operator could absorb it more easily than individual car owners.

\section{Easier Acceptance by the Interest Groups and General Public}

An initial emphasis on people-moving capacity clearly shows to the environmental and other interest groups as well as the general public that AHS is not a driving- 
encouraging or "business-as-usual" approach to solving the pressing congestion problem. The provision of a useful user service and the safety precautions would also help win public support. Increased fuel efficiency, reduced air pollutants, and improved ride quality can all contribute to public support.

This initial deployment is consistent with the major objectives of Federal APTS Program: increasing market share of transit and high occupancy vehicles, increasing transit safety, reducing transit operating costs and increasing revenue, improving energy efficiency, and reducing air pollution [Fisher, 1993].

\section{CONCLUSION}

Initial market penetration often involves many difficulties. This paper identified many important issues that may severely constrain initial AHS deployment. Many technological and non-lechnological difficulties involved in targeting the automobiles for initial AHS deployment are identified. Although an automobile-based AHS could be the final goal, it is not necessary that automobiles should be the very initial automation target. Recognizing these potential constraints and difficulties, it proposed an automated freeway shuttle van service for initial AHS deployment. Advantages as well as potential issues were also discussed.

The author believes that this initial deployment has a good chance of leading to a successful long-term AHS deployment supported by the general public. In addition, the proposed freeway shuttle van service could be a good candidate for the 1997 AHS demonstration required by ISTEA. After such a successful initial deployment, insights into and experience with such an AHS, together with public opinions, can be used to finalize future directions and phases of further AHS development. Note that the proposed initial deployment does not impose any constraint on the reachability of the many possible mature AHS. Possible mature systems include automobilebased AHS, transit-oriented AHS and systems that accommodate multiple major groups of vehicles. Possible transit-oriented AHS include one that offers region-wide automated freeway shuttle van/mini-bus services which enable connection of major activity centers through at most one transfer.

To the knowledge of the author, this is the first effort in the published literature for defining an initial AHS deployment target and for defining a candidate scenario for the 1997 demonstration. More research is needed to improve and refine the proposed deployment scenarios and to verify their feasibility. The author invites more research on identifying initial deployment constraints as well as on designing candidate AHS debut services.

\section{ACKNOWLEDGEMENT}

This work was performed as part of the California PATH Program of the University of California, in cooperation with the State of California Business, Transportation, and Housing Agency, Department of Transportation; and the United States 
Department of Transportation, Federal Highway Administration. The author would like to thank Drs. Steven Shladover, Stein Weissenberger and Mark Hickman of the PATH Program for their valuable comments on an earlier version of this paper. Valuable remarks offered in the refereeing process by Joseph Elias, Loren Bonderson and an anonymous referee are also greatly appreciated.

\section{REFERENCES}

Al-Ayat, R. and Hall, R.W., "A Conceptual Approach for Developing and Analyzing Alternate Evolutionary Deployment Strategies for Intelligent Vehicle/Highway Systems", PATH Program, Institute of Transportation Studies, University of California, Berkeley, UCB-ITS-PWP-94-05, 1994.

Bishop, J.R.. McHale, G.M, and W.B. Stevens, "A Snap Shot of the Automated Highway Systems (AHS) Precursor Systems Analyses (PSA) Early Research Results", Proceedings of IVHS America Fourth Annual Meeting, Atlanta, Georgia, April, 1994.

Elias, J., Stuart, D., Sweet, L and Kornhauser, A., "Practicality of Automated Highway Systems, Volume I: Summary Report", Final Report FHWA-RD-79-39, Office of Research and Development, FHWA, US DOT, Washington, D.C., 1977.

Federal Highway Administration (FHWA), United States Department of Transportation, Human Factors Design of Automated Highway Systems, Contract DTFH61-92-C-00100, 1992(a).

Federal Highway Administration, "Precursor Systems Analyses of Automated Highway Systems", (BAA) RFP No. DTFH61-93-R-00047, 1992(b).

Federal Highway Administration, AHS Human Factors Workshop, Orlando, Florida, Feb. 8, 1993.

Fisher, R., "FTA Update on the APTS Program", presented at the 72 nd Annual Transportation Research Board Meeting, Jan. 10-14, 1993.

Hall, R.W. and Tsao, H.-S.J., "AHS Deployment: A Preliminary Assessment of Uncertainties", PATH Program, Institute of Transportation Studies, University of California, Berkeley, UCB-ITS-PWP-94$02,1994$.

Koppelman, F.S., Bhat, C.R. and Schofer, J.L., "Market Research Evaluation of Actions to Reduce Suburban Traffic Congestion: Commuter Travel Behavior and Response to Demand Reduction Actions", Transportation Research - A, Vol. 27A, No. 5, pp. 383-393, 1993.

Lowe, M.D., "Road to Nowhere", World Watch, May/June 1993.

Shladover, S., "Operation of Automated Guideway Transit Vehicles in Dynamically Reconfigured Trains and Platoons," (Extended Summary, Vol. I \& II), UMTA-MA-06-0085-79-1, UMTA-MA-06-0085-792 and UMTA-MA-06-0085-79-3, U.S. Department of Transportation, Urban Mass Transportation Administration, Washington, D.C., July, 1979.

Slater, R.E., Awards Luncheon Speech, IVHS America Fourth Annual Meeting, Atlanta, Georgia, April 19, 1994.

Stevens, W.B., "The Automated Highway System (AHS) Concept Analysis", MITRE Research Report MTR-93W0000123, McLean, Virginia, 1993.

Stevens, W.B., "Goals and Definitions of Automated Highway System Concepts", Proceedings of IVHS America Fourth Annual Meeting, Atlanta, Georgia, April, 1994.

Teal, R.F., "Using Smart Technologies to revitalize Demand Responsive Transit", IVHS Journal, 1994, Vol. 1(3), pp. 275-293.

TRB (Transportation Research Board), Special Report 170 (Proceedings of a 1974 conference on Dual Mode Transportation), National Academy of Science, Washington, D.C., 1976.

Tsals, I., Boghani, A.B. and Greichen, J.J. "IVHS-Lessons from Other Industries", Proceedings of IVHS America Third Annual Meeting, Washington, D.C., April, 1993.

Tsao, H.-S.J, Hall, R.H. and Shladover, S.E.. "Design Options for Operating Automated Highway Systems", Proceedings of Vehicle Navigation \& Information Systems Conference, Ottawa, Canada, Oct. 1993, 494-500, 1993(a).

Tsao, H.-S.J., Hall, R.W., and Shladover, S.E., Plocher, T.A. and Levitan, L.J., "Human Factors Design of Automated Highway Systems: Firsi Generation Scenarios", FHWA Report No. FHWA-RD-93-123, Washingion, D.C., 1993(b).

Tsao, H.-S.J., Plocher, T.A., Zhang, W.-B. and Shladover, S.E., "Human Factors Design of Automated Highway Systems: Second Generation Scenarios", in preparation, to be published as an FHWA Report, Washington, D.C., 1994. 